\title{
Inhibition of CREB activity in the dorsal portion of the striatum potentiates behavioral responses to drugs of abuse
}

\author{
Stefania Fasano ${ }^{1}$, Christopher Pittenger ${ }^{2}$ and Riccardo Brambilla ${ }^{1 *}$ \\ 1 Institute of Experimental Neurology, Division of Neuroscience, San Raffaele Foundation and University, Milano, Italy \\ 2 Division of Molecular Psychiatry, Department of Psychiatry, Yale University, New Haven, CT, USA
}

Edited by:

Serge Laroche,

CNRS and Université Paris Sud, France

Reviewed by:

Bruno Bontempi, CNRS and Université

de Bordeaux, France

Kobi Rosenblum, Haifa University, Israel

${ }^{*}$ Correspondence:

Riccardo Brambilla, Institute of

Experimental Neurology, Division of

Neuroscience, San Raffaele Foundation and University, Via Olgettina 58, 20132

Milano, Italy.

e-mail: brambilla.riccardo@hsr.it
The striatum participates in multiple forms of behavioral adaptation, including habit formation, other forms of procedural memory, and short- and long-term responses to drugs of abuse. The cyclic-AMP response element binding protein (CREB) family of transcription factors has been implicated in various forms of behavioral plasticity, but its role in the dorsal portion of the striatum-has been little explored. We previously showed that in transgenic mice in which CREB function is inhibited in the dorsal striatum, bidirectional synaptic plasticity and certain forms of long-term procedural memory are impaired. Here we show, in startling contrast, that inhibition of striatal CREB facilitates cocaine- and morphine-place conditioning and enhances locomotor sensitization to cocaine. These findings propose CREB as a positive regulator of dorsal striatumdependent procedural learning but a negative regulator of drug-related learning.

Keywords: CREB, dorsal striatum, cocaine, morphine, locomotor sensitization, conditioned place preference

\section{INTRODUCTION}

Transcription factors of the cyclic-AMP response element binding protein (CREB) family, and the signaling cascades that regulate them, have been shown to importantly contribute to memory formation and long-term synaptic plasticity both in invertebrate systems and in several areas of the mammalian brain (Dash et al., 1990; Bourtchuladze et al., 1994; Yin et al., 1994; Bartsch et al., 1998; Ahn et al., 1999; Josselyn et al., 2001, 2004; Barco et al., 2002, 2005; Kida et al., 2002; Pittenger et al., 2002, 2006; Han et al., 2007, 2009; Lopez de Armentia et al., 2007; Lee et al., 2008; Jancic et al., 2009; Mamiya et al., 2009; Viosca et al., 2009a,b). Inhibition of this class of transcriptional activators leads to memory impairments, while their potentiation can facilitate memory consolidation (Barco et al., 2003; Carlezon et al., 2005; Josselyn and Nguyen, 2005). Dysregulation of memory formation may contribute to neuropsychiatric diseases - either to memory impairments, or to maladaptive, inappropriate, or inflexible patterns of behavior or thought. In one prominent example, the underlying molecular mechanisms implicated in drug addiction have been found to overlap with mechanisms involved in memory formation in many respects (Berke and Hyman, 2000; Fasano and Brambilla, 2002; Chao and Nestler, 2004; Kelley, 2004; Hyman et al., 2006). Addiction is characterized by a transition from reward-based substance consumption for recreational reasons to compulsive, pathological drug use that is resistant to voluntary control. The cognitive basis of this transition has been linked to the formation of maladaptive habits, in which aberrant stimulus-response associations, normally acquired through multiple repetitions of goal directed learning processes, become independent of the reinforcing properties of the drug in question (Everitt and Robbins, 2005; Belin et al., 2009).

A key brain region involved in procedural learning, habit formation and drug addiction is the striatum. The dorsal portion of this brain region is generally considered to have a role in motor control and habit formation, while its ventral extension, the nucleus accumbens (NAc), has been implicated in the reward mechanisms to natural and drug reinforcers. The few studies examining the normal function of CREB in the dorsal striatum have confirmed a role in striatum-dependent learning and memory (Hernandez et al., 2002; Pittenger et al., 2006; Lee et al., 2008). We previously found that expression of a dominant negative mutant of CREB, KCREB, in the dorsal portion of the striatum causes a bidirectional loss of long-term corticostriatal plasticity and a concomitant impairment in procedural memory formation (Pittenger et al., 2006). In contrast, CREB in the NAc is upregulated by treatment with psychostimulants and appears to homeostatically oppose some of their effects (Carlezon et al., 1998, 2005; Pliakas et al., 2001; Barrot et al., 2002; Sakai et al., 2002; McClung and Nestler, 2003; Dong et al., 2006; Dinieri et al., 2009). Overexpression of dominant-negative versions of CREB in the NAc lead to increased sensitivity to both psychostimulants and opiates, while ectopic expression of wildtype (WT) CREB inhibits the behavioral responses to drugs of abuse. This cumulative evidence suggests a rather complex drugdependent adaptive response to an altered CREB activity in this brain structure.

Previously, the effect of CREB blockade in the striatum on drugrelated behaviors has only been evaluated in the NAc. Here we show, in a mouse line that predominantly expresses KCREB in the dorsal striatum but little in the ventral portion (str-KCREB), that blockade of CREB activity results in an enhancement of the rewarding effects of cocaine and morphine, indicating that CREB in the dorsal striatum plays a similar role in antagonizing the effects of psychostimulants.

\section{MATERIALS AND METHODS ANIMALS}

We have previously described the generation and initial characterization of str-KCREB transgenic mice (Pittenger et al., 2002, 2006). 
str-KCREB mutants and littermate controls used in behavioral experiments were backcrossed for more than seven generations onto the C57BL/ 6 congenic strain. Behavioral studies and animal care were conducted according to protocols approved by the Animal Care and Use Committee of the Fondazione San Raffaele del Monte Tabor (IACUC 229) and communicated to the Ministry of Health and local authorities.

\section{IMMUNOHISTOCHEMISTRY CREB immunostaining}

str-KCREB mice and WT littermates were perfused transcardially with ice-cold 4\% PFA dissolved in $0.1 \mathrm{M} \mathrm{Na}_{2} \mathrm{HPO}_{4} / \mathrm{NaH}_{2} \mathrm{PO}_{4}$ buffer, $\mathrm{pH}$ 7.4. Brains were postfixed overnight and transferred to $25 \%$ buffered sucrose for $24 \mathrm{~h}$. Coronal sections were cut at $30 \mu \mathrm{m}$ thickness on a freezing microtome and stored in a cryoprotective solution at $-20^{\circ} \mathrm{C}$ until they were processed for immunohistochemistry as previously described (Fasano et al., 2009). Free-floating sections were rinsed in TBS and incubated in TBS containing 3\% $\mathrm{H}_{2} \mathrm{O}_{2}$ and $10 \%$ methanol for $15 \mathrm{~min}$. After rinsing in fresh TBS, sections were blocked in 5\% normal goat serum and $0.1 \%$ Triton X-100 in TBS for $1 \mathrm{~h}$. Anti-CREB primary antibody (1:200; Cell Signaling Technologies) was used overnight at $4^{\circ} \mathrm{C}$ to detect protein expression. Tissue sections were further processed using Vectastain Elite ABC kit (Vector Labs) and DAB detection. For analysis, great care was taken to match sections through the same region of brain at the same level. All visible positive nuclei or cell bodies within a $10 \times 10$ field were counted and expressed as number of cells per square millimeter of tissue for each brain site. For a single brain site, counts were averaged from three sections from each animal and six animals were analyzed for each genotype. Quantification of CREB positive neurons was counted from dorsal striatum $(\mathrm{CPu})$ and its ventral portion (NAc). Sample areas were visualized under a $10 \times$ objective in a Leica DM IRB microscope by a blind investigator to condition and genotype and analyzed using the ImageJ software.

\section{Cholinesterase staining}

It was carried out on $30 \mu \mathrm{m}$ fresh frozen sections of dissected mouse brain. They were lightly fixed with $2 \%$ PFA ( $5 \mathrm{~min}$, room temperature) and then stained with a 9:1 mixture of solution A $(0.5 \mathrm{mg} / \mathrm{ml}$ acetylthiocholine, $0.5 \mathrm{mM}$ sodium citrate, $3 \mathrm{mM}$ $\mathrm{CuSO}_{4}, 0.1 \mathrm{M}$ acetate buffer, $\mathrm{pH}$ 6.0) and solution $\mathrm{B}$ ( $5 \mathrm{mM}$ potassium ferricyanide), heated to $37^{\circ}$ and mixed immediately before use. Slides were incubated at $37^{\circ}$ for $5 \mathrm{~min}$ and then rinsed gently with tap water. They were then developed with $0.6 \mathrm{mg} / \mathrm{ml}$ chloronaphthol in $\mathrm{PBS} / 0.025 \% \mathrm{H}_{2} \mathrm{O}_{2}$.

\section{D1 and $D 2$ binding}

Fresh-frozen dissected mouse brains were sliced at $30 \mu \mathrm{m}$ on a microtome. Unfixed slides were washed for $30 \mathrm{~min}$ in $50 \mathrm{mM}$ Tris-Cl (pH 7.4), $120 \mathrm{mM} \mathrm{NaCl}, 5 \mathrm{mM} \mathrm{KCl}, 2 \mathrm{mM} \mathrm{CaCl}, 1 \mathrm{mM}$ $\mathrm{MgCl}_{2}$, and $0.3 \% \mathrm{BSA}$ (for D1 binding) or in $50 \mathrm{mM}$ Tris-Cl ( $\mathrm{pH}$ 7.4), $100 \mathrm{mM} \mathrm{NaCl}$, and 0.3\% BSA (for D2 binding). Slides were then incubated at room temperature in the same buffer plus $50 \mathrm{nM}$ ketanserin/2 nM ${ }^{3} \mathrm{H}-\mathrm{SCH} 23390$ (for D1 binding) or $100 \mathrm{nM}$ ketanserin/1 nM ${ }^{3} \mathrm{H}$-spiperone (for D2 binding). Negative controls (not shown) for nonspecific binding were performed with the same incubation buffer plus $5 \mu \mathrm{M}$ butaclamol (which binds both D1 and D2 receptors). After ligand binding, slides were rinsed twice for $10 \mathrm{~min}$ in the same buffer, allowed to dry, and exposed to ${ }^{3} \mathrm{H}$ Hyperfilm (Amersham) for 4 weeks.

Measurement of the hybridization signal was carried out on three coronal sections using ImageJ software. Optical density value relative to each receptor was reported after subtraction of the tissue background (as determined on the cortex in each section).

\section{HPLC assay of monoamines and their metabolites}

Anesthetized mice were perfused with ice-cold PBS. Hippocampi and striata were rapidly dissected from 10 transgenics and 10 controls and frozen on dry ice/ethanol. Monoamines were extracted and analyzed by high-performance liquid chromatography as described (Pittenger et al., 2002).

\section{BEHAVIORAL ANALYSIS}

\section{Locomotor activity}

Mice were placed in individual locomotor activity monitoring boxes, consisting of a plastic, transparent rectangular area (Ugo Basile, Comerio, Italy) equipped with infrared light photocell beams, as previously described (Mazzucchelli et al., 2002; Fasano et al., 2009). Horizontal activity was recorded during 10 min test session for three consecutive days in a low luminosity environment (20 lx).

\section{Rotarod}

Mice were placed on an accelerating rotarod (Ugo Basile, Comerio, Italy) at a slow rotation speed ( $4 \mathrm{rpm}$ ) and must continuously walk to keep from falling off the cylinder. Rotational speed was gradually increased to a maximum of $40 \mathrm{rpm}$ over a 5 -min session. Performance was measured as latency to fall and was monitored during three daily sessions for two consecutive days (Fasano et al., 2009).

\section{Morris water maze}

The water maze experiment was carried out in a $122-\mathrm{cm}$ diameter mouse Morris water maze apparatus and analyzed using Hvswater ${ }^{\oplus}$, as previously described (Pittenger et al., 2002). Mice were trained for 10 consecutive days with a hidden platform (four trials/day, $20 \mathrm{~min}$ ITI) prior to a probe trial on day 11 .

\section{Conditioned place preference}

An unbiased place conditioning procedure was performed as previously described (Mazzucchelli et al., 2002; Fasano et al., 2009). The place preference apparatus consisted of two different Plexiglas compartments separated by a central neutral area. It was located in a sound proof testing room with low luminosity ( $25 \mathrm{~lx})$. No group showed initial preference for any chamber. Treatments were counterbalanced between compartments. The schedule consists of three different phases: pre-conditioning phase: mice were placed in the middle of the neutral area and their location recorded for $18 \mathrm{~min}$; conditioning phase: mice were treated for six consecutive days with alternate drug (days 1, 3, and 5) or saline (days 2, 4, and 6) injection, each paired with one of the two compartments. Two different doses of cocaine were used 5 and $15 \mathrm{mg} / \mathrm{kg}$, i.p. and one dose of morphine $(5 \mathrm{mg} / \mathrm{kg}$, s.c.). Saline treated mice received saline on all 6 days; post-conditioning phase: the test was conducted $24 \mathrm{~h}$ after the final conditioning session. Place preference was quantified in 
terms of time spent in drug-paired side. A score was calculated for each mouse as the difference between post-conditioning and preconditioning time spent in drug-paired compartment.

\section{Locomotor sensitization}

Locomotor sensitization to repeated cocaine administration ( 5 and $15 \mathrm{mg} / \mathrm{kg}$, i.p.) was measured as previously described (Fasano et al., 2009). For the first 3 days mice were placed in the locomotor activity boxes immediately after saline injections and horizontal locomotor activity was measured during $10 \mathrm{~min}$. On day 4 mice were divided into groups that received daily cocaine or saline injections as indicated. On day 11 (for the $5 \mathrm{mg} / \mathrm{kg}$ cocaine protocol) or on day 9 (for the $15 \mathrm{mg} / \mathrm{kg}$ cocaine protocol), all the mice received saline injections and placed for $10 \mathrm{~min}$ in the test boxes in order to evaluate the conditioned locomotor activity. After 10 days of drug-free state mutants and sibling controls received a challenge of cocaine and locomotor activity was assessed.

\section{STATISTICAL ANALYSIS}

Behavioral data were analyzed using two-way ANOVA with genotype, time or drug as factors of variation. Subsequent one-way ANOVAs were calculated after significant main effects of the twoway ANOVA followed by Scheffé post hoc test for specific comparisons. Statistical analysis was performed with SPSS. $t$-Test was used to assess the lack of difference for HPLC samples.

\section{RESULTS}

\section{STRIATAL LOCALIZATION OF THE KCREB TRANSGENE}

We previously reported that in the str-KCREB line transgene expression is largely confined to the dorsal portion of the striatum, as demonstrated by in situ hybridization and western blotting (Pittenger et al., 2006). In order to determine more precisely KCREB protein localization, we performed immunohistochemical analysis using specific antibodies against CREB. By comparing str-KCREB and control mice we confirmed a significant increase in the number of CREB positive cells associated to the dorsal portion of the striatum in the transgenic mice, with no changes of immunoreactivity in the NAc (Figures 1A-D). Quantification of CREB positive cells (Figure 1E) confirms that in this mouse line, expression of KCREB is striatal specific, with a marked localization to the dorsal portion of this brain region.

\section{NORMAL NEUROCHEMICAL ORGANIZATION IN THE Str-KCREB MICE}

Previous reports indicate that loss of CREB activity may cause neurodegeneration (Mantamadiotis et al., 2002). Our earlier observations indicate that synaptic plasticity is lost in the dorsal portion of the striatum, in marked contrasts with normal responses in both the hippocampus and the NAc and that may impact on the observed loss of long-term memory in instrumental learning (Pittenger et al., 2006). Therefore, we were concerned that some minor anatomical alterations in the dorsal striatum may be caused by a chronic inhibition of CREB in the str-KCREB line, possibly causing complications in the interpretation of the behavioral and electrophysiological results. Thus, we used cholinesterase staining, which detects anatomical differences in the striatum. The striatum can be neurochemically divided in two district regions, termed "striosomes" and "matrix", which have different connectivity and functional relevance. Striosomes appear in cholinesterase staining as pale patches dispersed in the dark background represented by the matrix.

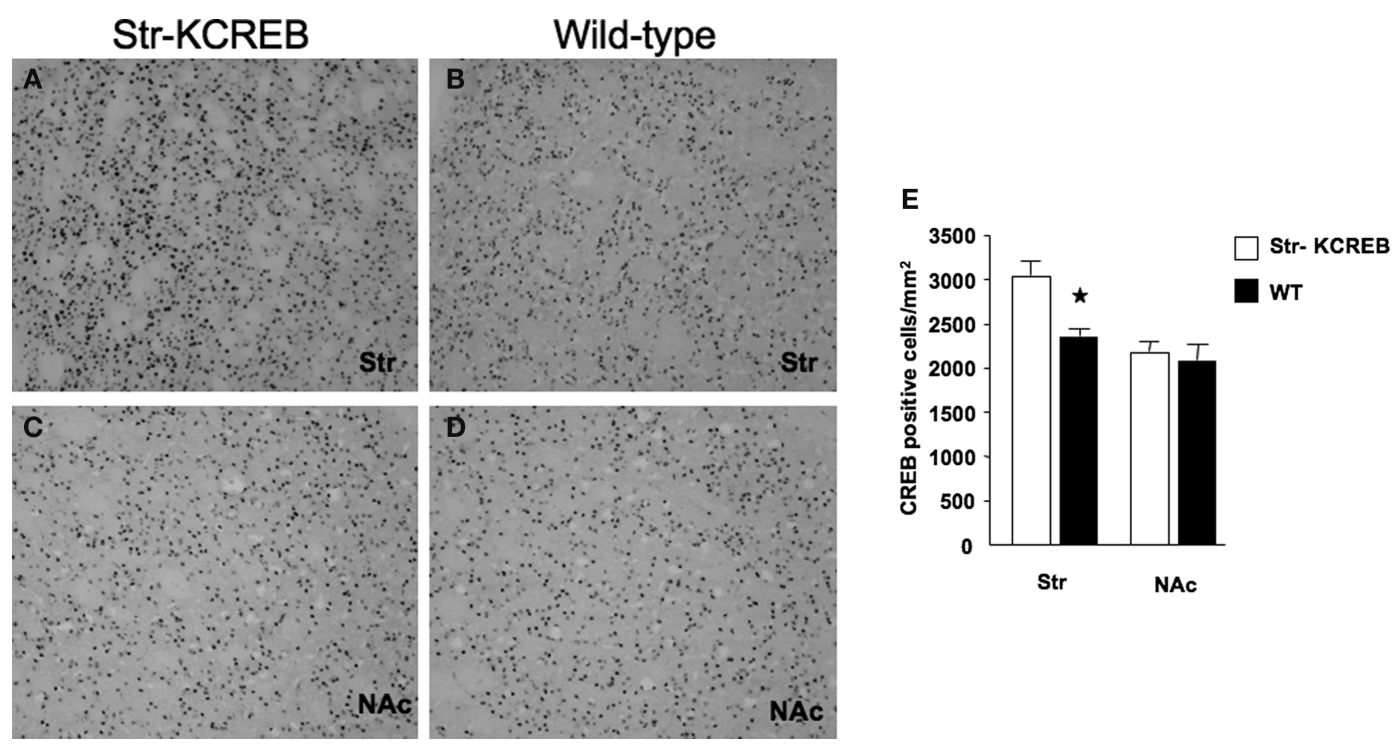

FIGURE 1 | Immunohistochemical characterization of KCREB expression in str-KCREB mice. Sections from str-KCREB and control mice stained with an anti-CREB antibody, which recognizes both endogenous CREB and KCREB, showed increased CREB immunoreactivity in the nuclei of dorsal striatum (str) neurons of str-KCREB mice (A) relative to wild-type (WT) controls (B). In the accumbens region (NAC), of str-KCREB animals (C) the levels of the transgene were much lower than in dorsal portion, and CREB immunoreactivity was comparable relative to control mice (D). There was no significant increase in CREB immunoreactivity in the cortex (cx) or in the hippocampus or amygdala (not shown). (E) Quantification of CREB positive cells in the dorsal portion of the striatum (str) and its ventral area, the nucleus accumbens (NAc). Data are expressed as mean \pm SEM. Two-way ANOVA showed a significant effect of the brain region in str-KCREB animals $(n=6)$ in comparison to WT controls $(n=6)$. ${ }^{*} P<0.01$. 
As shown in Figures 2A,B, str-KCREB mice show normal striatal morphology when stained with thiocholine iodide to identify acetylcholinesterase. Higher magnification images also detect striosomes, both in the transgenic and in the control striata

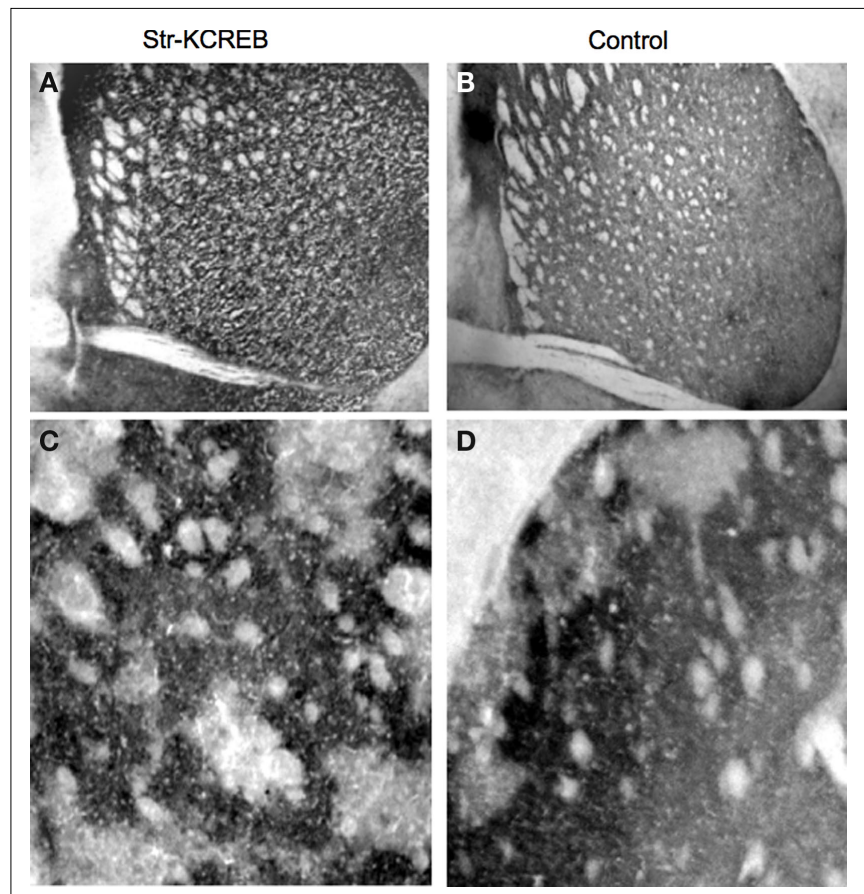

FIGURE 2 | str-KCREB mice have normal striatal morphology as revealed by acetylcholinesterase staining. Fresh frozen brain sections from str-KCREB mice and wt controls were stained with thiocholine iodide to identify acetylcholinesterase. Cholinesterase staining shows normal striatal anatomy (A) and preserved striosomes (C) in str-KCREB transgenic mice and wt littermate controls, respectively (B,D).
(Figures 2C,D), confirming that the general architecture of the striatum is not altered in the str-KCREB animals.

Next, we performed an in situ binding study with specific radioligands for both D1 - and D2-like receptors, in order to determine potential alterations in the dopaminergic system of the str-KCREB mice. As reported in Figure 3, no major differences in the binding were found between transgenic (A and $\mathrm{C}$ ) and control striata (B and D), suggesting that at the dopamine receptor level KCREB expression appears normal (see quantification in panel E). Finally, as indicated in Figure 4, levels of dopamine and other monoamines, as well as their metabolites, were not significantly different between str-KCREB mice and their controls, either in the striatum (A) or in the hippocampus (B).

Altogether, these results indicate that str-KCREB mice are fairly intact at the neurochemical level.

\section{Str-KCREB ANIMALS SHOW NORMAL BASAL ACTIVITY, MOTOR COORDINATION, SPATIAL LEARNING, AND OTHER CONTROL BEHAVIORS}

We tested a number of control behavioral parameters and found them to be normal. Transgenic mice showed no abnormalities in a general neurological screen (Table 1). Though male transgenic mice have previously been shown to exhibit increased locomotion in the open field when backcrossed only a few generations on to the C57BL/6 congenic line (Pittenger et al., 2002), further backcrossing (seven generations) eliminated this difference, and the mice used in the behavioral experiments described here showed normal locomotion and habituation in activity boxes, a test similar to the open field (Figure 5A). In addition, motor coordination and motor learning as assayed in the rotarod were found to be normal (Figure 5B).

We previously showed that spatial memory is intact in these mice, consistent with the lack of expression of the transgene in the hippocampus (Pittenger et al., 2002, 2006). We have performed the Morris water maze after several backcrosses in the C57 background and we
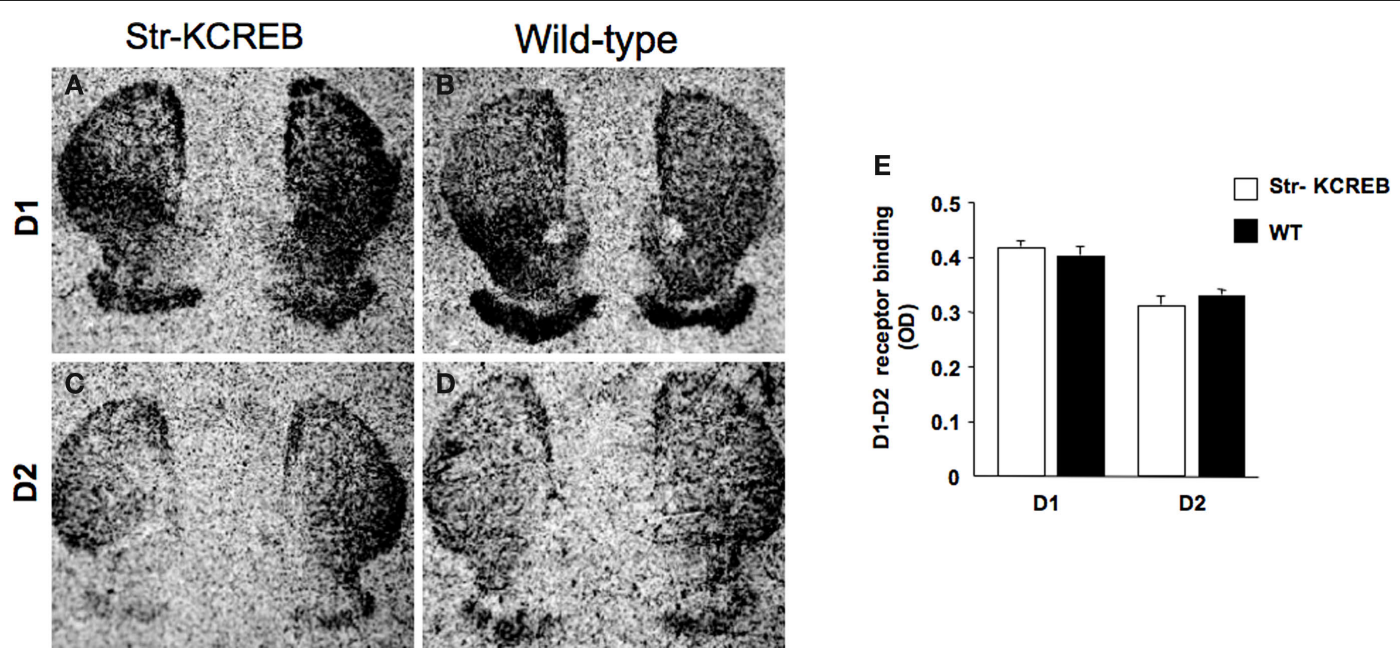

FIGURE 3 | str-KCREB animals show normal D1 and D2 receptor binding patterns, as visualized by radioligand binding. Slices from fresh frozen brains of str-KCREB and control mice were probed with D1 $(\mathbf{A}, \mathbf{B})$ and D2 radioligands (C,D). (E) Optical density $(O D)$ value relative to each receptor was expressed as mean $\pm \operatorname{SEM}(n=3,3)$. No quantitative differences are evident in either receptor class, indicating that the postsynaptic component of the nigrostriatal dopaminergic modulatory system is normal in these animals. 
A

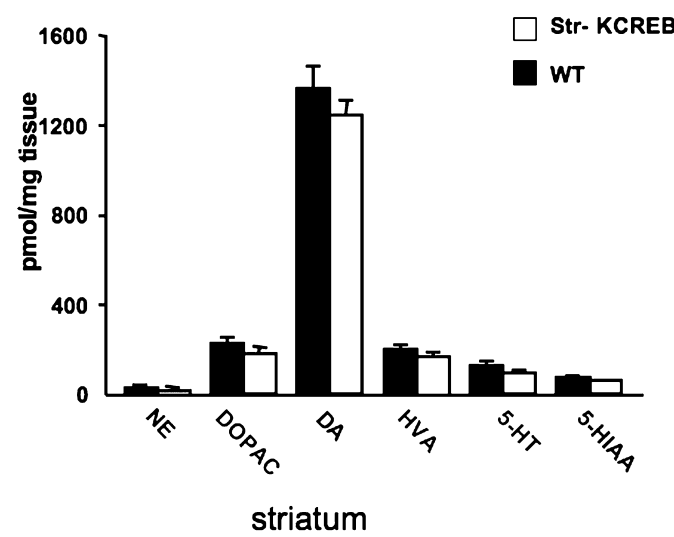

FIGURE 4 | str-KCREB animals have normal levels of dopamine, its metabolites, and other monoamines, in striatum and hippocampus. Striata and hippocampi were dissected from str-KCREB and littermates controls, and the tissue was assayed by HPLC for modulatory monoamine transmitters and their metabolites. No significant differences were seen between str-KCREB
B

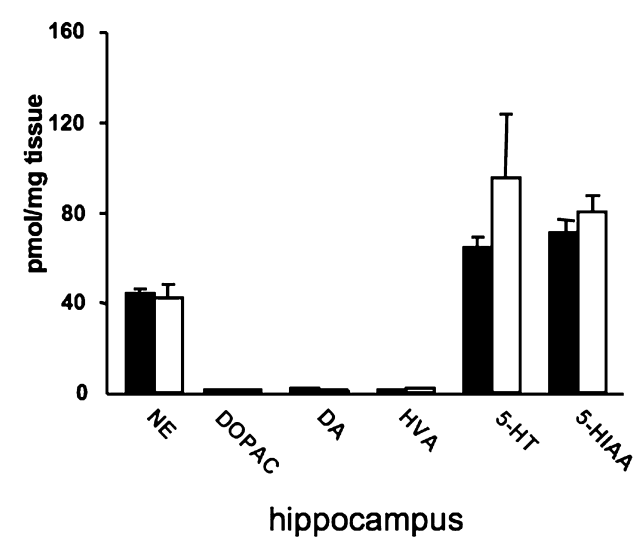

mice $(n=10)$ and controls $(n=10)$ in striatum $(\mathbf{A})$, in which dopamine is abundant ( $t$-test $P=0.68$ ) or in hippocampus $(\mathbf{B})$ in which norepinephrine ( $t$-test $P=0.51$ ) and serotonin ( $t$-test $P=0.15$ ) are present. NE, norepinephrine; DOPAC, 3,4-dihydroxyphenylacetic acid; DA, dopamine; HVA, homovanillic acid; 5-HT, 5-hydroxytryptophan; 5-HIAA, 5-hydroxyindole acetic acid.
Table 1| Str-KCREB mice showed no abnormalities in a general neurological screen.

\begin{tabular}{|c|c|c|c|c|c|}
\hline Variable & $\begin{array}{l}\text { str- } \\
\text { KCREB }\end{array}$ & SEM & Ctrl & SEM & $\begin{array}{c}\text { Uncorrected } \\
P \text { value }\end{array}$ \\
\hline Weight (g) & 17.3 & 0.90 & 16.5 & 35 & 0.433 \\
\hline Body position & 4.0 & 0.32 & 4.2 & 0.37 & 0.694 \\
\hline Locomotion & 3.0 & 0.32 & 3.2 & 0.58 & 0.771 \\
\hline Respiratory rate & 5.6 & 0.51 & 7.0 & 0.55 & 0.098 \\
\hline Arousal & 3.4 & 0.24 & 4.0 & 0.41 & 0.227 \\
\hline Spatial exploration & 3.0 & 0.71 & 3.4 & 0.87 & 0.731 \\
\hline Piloerection & 2.2 & 0.37 & 2.0 & 0.45 & 0.740 \\
\hline Startle response & 2.2 & 0.73 & 2.2 & 0.58 & 1.000 \\
\hline Pelvic elevation & 3.0 & 0.55 & 3.6 & 0.24 & 0.347 \\
\hline Tail elevation & 2.9 & 0.33 & 1.9 & 0.24 & 0.042 \\
\hline Visual reach & 6.4 & 0.24 & 5.6 & 0.40 & 0.126 \\
\hline Grip strength & 5.4 & 0.24 & 4.8 & 0.80 & 0.494 \\
\hline Body tone & 5.6 & 0.24 & 5.4 & 0.24 & 0.580 \\
\hline Pinna reflex & 3.8 & 0.49 & 4.4 & 0.51 & 0.421 \\
\hline Cornea reflex & 5.0 & 0.55 & 3.7 & 0.30 & 0.071 \\
\hline Struggle & 3.0 & 0.63 & 3.6 & 0.24 & 0.402 \\
\hline Wire grip & 1.4 & 0.75 & 2.6 & 1.44 & 0.480 \\
\hline Hang time (sec) & 54.6 & 5.40 & 35.4 & 12.24 & 0.189 \\
\hline Smooth incline & 3.2 & 0.73 & 3.2 & 0.20 & 1.000 \\
\hline Skin color & 4.0 & 0.32 & 4.2 & 0.49 & 0.740 \\
\hline Limb tone & 3.2 & 0.66 & 3.8 & 0.48 & 0.544 \\
\hline Abdominal tone & 5.2 & 0.20 & 4.2 & 0.37 & 0.046 \\
\hline Pupil size & 1.8 & 0.20 & 2.1 & 0.24 & 0.371 \\
\hline Provoked biting & 2.6 & 1.08 & 2.4 & 0.98 & 0.894 \\
\hline Tail pinch response & 3.1 & 0.46 & 3.8 & 0.58 & 0.373 \\
\hline Biting tendency & 0.3 & 0.20 & 0.8 & 0.20 & 0.115 \\
\hline Provoked freezing & 0.4 & 0.19 & 0.6 & 0.19 & 0.471 \\
\hline Vocalizations & 0.4 & 0.40 & 1.6 & 0.87 & 0.246 \\
\hline Urination/defecation & 4.0 & 0.55 & 2.8 & 0.92 & 0.294 \\
\hline
\end{tabular}

found no differences in the learning profile between transgenic and control animals (Figure 6A). When a probe trial was performed at the end of the learning procedure, as indicated in Figure 6B, both animal groups show a strong selectivity for the target quadrant. There was no significant difference between genotypes further confirming that spatial memory in the str-KCREB mice can be consolidated.

Altogether these data indicate that str-KCREB mice are normal in a number of neurological parameters, as well as in locomotor behavior, motor coordination and spatial memory.

\section{str-KCREB MICE SHOW ENHANCED REWARD-RELATED LEARNING}

Previous studies have shown that reduction of CREB function specifically in the NAc shell enhances the rewarding effects of cocaine and morphine in the place preference test - that is, animals with reduced CREB activity spend more time in the drug-paired compartment than control littermates (Carlezon et al., 1998; Barrot et al., 2002). This stands in marked contrast to the role of CREB demonstrated in our previous publication on the str-KCREB mice, in which a reduction in dorsal striatal CREB function impairs striatum-dependent learning (without any drug reinforcement) - that is, that str-KCREB animals, with reduced CREB activity in the striatum, learn less well than littermate controls (Pittenger et al., 2006).

To assess the rewarding properties of cocaine in str-KCREB mice, we tested them in conditioned place preference (CPP, Maldonado et al., 1997; Mazzucchelli et al., 2002; Ferguson et al., 2006; Fasano et al., 2009). In this task, animals repeatedly receive drug injections in a specific context; their subsequent preference for that context reflects its association with the drug reward. When given a low dose of cocaine $(5 \mathrm{mg} / \mathrm{kg}$ i.p.), str-KCREB showed a clear preference for the cocaine-paired context than control mice (two-way ANOVA, genotype effect, $F_{1,28}=21.37, P<0.0001$, Figure 7A). When given a higher dose of cocaine ( $15 \mathrm{mg} / \mathrm{kg}$ i.p.), both genotypes again showed clear preference for the drug-paired 


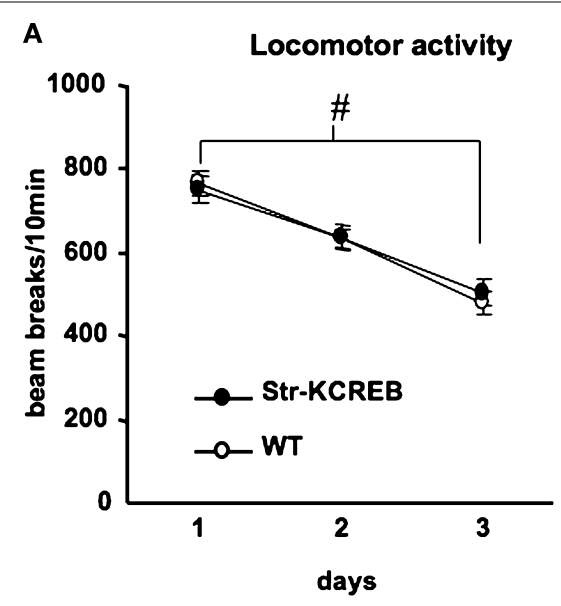

FIGURE 5 | Normal locomotor activity and coordination in str-KCREB mice. (A) Transgenics and littermate controls ( $n=40,40)$ were examined for locomotor behavior in activity boxes. str-KCREB mice and wild-type controls were monitored in activity boxes equipped with infrared photocell beams (10 min exploratory sessions on three consecutive days). str-KCREB mice habituated normally to the test environment, manifesting a significant decrease in spontaneous

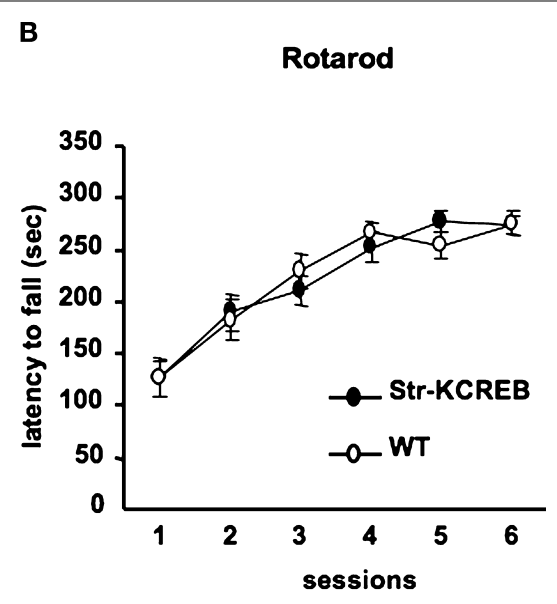

locomotion ( $P<0.0001$ main effect of day). No difference was seen between str-KCREB mice and sibling controls. (B) str-KCREB mice showed normal motor learning and coordination on accelerating rotarod, three trials/day, 2 days. Mice walked forward on a rotating cylinder at speeds increasing from 4 to 40 rpm over a 5 -min test session. str-KCREB mice and sibling controls ( $n=21,21)$ showed equivalently improved latency to fall (mean \pm SEM) across trials.

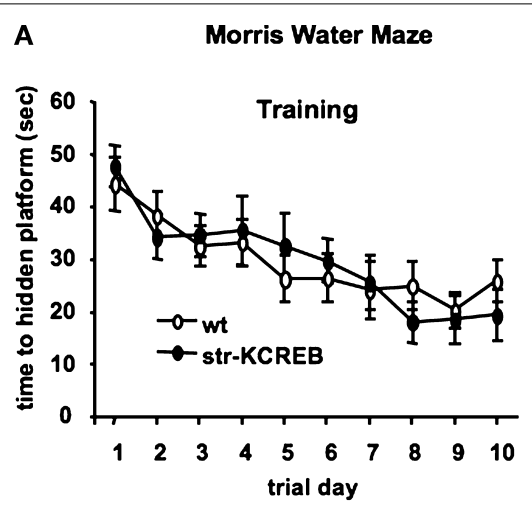

FIGURE 6 | Normal spatial memory in Morris water maze in str-KCREB mice. Animals were trained in the hidden-platform Morris water maze for 10 consecutive days (four trials/day; 20 min ITI) and then tested with a probe trial on day 11. (A) str-KCREB mice showed normal acquisition curve during the training days. ANOVA for repeated measures, revealed main effect of day $P<0.001$, no effect of genotype

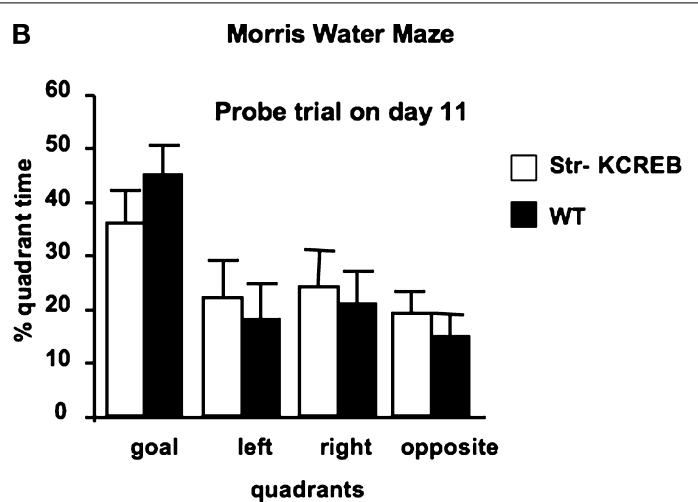

$P=0.985$ and no genotype $\times$ day interaction $P=0.912$. (B) Spatial memory is shown as \% of quadrant occupancy time during the probe trial measured $24 \mathrm{~h}$ after training. Both genotypes spent most of the time in the goal quadrant (ANOVA repeated measures, spatial effect, $P<0.01$ ), with no significant differences between genotypes $(n=10,10)$, group effect on goal occupancy, $P>0.1$. context $\left(F_{1,46}=83.52, P<0.0001\right)$, but str-KCREB and control mice showed equivalent learning $\left(F_{1,28}=0.60, P=0.44\right)$; this may represent a ceiling effect at the higher drug concentration. Inhibition of striatal CREB therefore enhances reward-related learning. This finding is consistent with previous data on CREB inhibition in the accumbens shell, but it stands in marked contrast to our demonstration that disruption of striatal CREB impairs procedural learning and bidirectional long-term synaptic plasticity in the same animals.

To test the generality of this result, we tested CPP in response to morphine. Initial reports in global CREB hypomorph mice indicated enhanced CPP to cocaine but impaired CPP to mor- phine (Walters and Blendy, 2001). However, disruption of CREB function by other means has shown an enhancement of morphine CPP, suggesting that the dissociation between cocaine and morphine effects in the original hypomorph mice derives from compensatory or developmental effects (Barrot et al., 2002). Consistent with these latter results, we found a marked enhancement in sensitivity to the rewarding properties of morphine $(5 \mathrm{mg} / \mathrm{kg}$, s.c.) in str-KCREB transgenic mice, relative to sibling controls (genotype effect, $F_{1,23}=9.76, P<0.01$, Figure 7B). This supports a role for striatal CREB in downregulating the capacity of both psychostimulants and opiate drugs to act as primary rewards in CPP. 


\section{Place Preference}
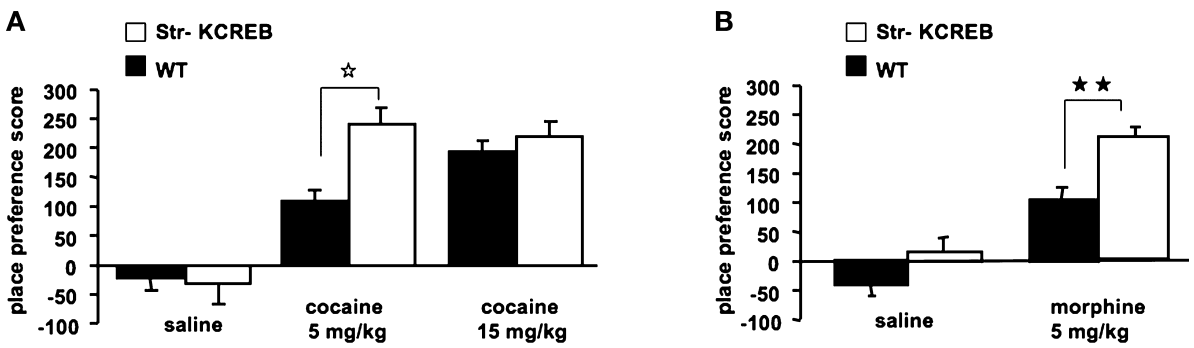

FIGURE 7 | Enhanced reward-related learning in str-KCREB mice. (A) str-KCREB mice showed enhanced conditioned place preference to cocaine. Conditioned place preference is expressed as difference between post-and pre-conditioning time spent in the drug-paired compartment of the training apparatus ( $n$ : saline 10,10; $5 \mathrm{mg} / \mathrm{kg}$ i.p. cocaine 15,15; $15 \mathrm{mg} / \mathrm{kg}$ i.p. cocaine 15,15; all values mean \pm SEM). (B) str-KCREB mice showed enhanced conditioned place preference to morphine $(5 \mathrm{mg} / \mathrm{kg}$, s.c., $n=13$ transgenic, 12 control) or saline ( $n=11$ transgenic, 12 control; all values mean \pm SEM). Two-way ANOVA, genotype effect: ${ }^{*} P<0.01$; $P<0.0001$.

\section{Str-KCREB MICE SHOW ENHANCED SENSITIZATION OF THE LOCOMOTOR RESPONSE TO REPEATED ADMINISTRATION OF COCAINE}

Acute cocaine administration increases locomotion. This response increases when cocaine is administered on consecutive days, a phenomenon known as sensitization of the locomotor response (Robinson and Berridge, 1993; Mazzucchelli et al., 2002; Ferguson et al., 2006; Fasano et al., 2009). Previous studies have suggested that manipulations of CREB can influence sensitization (Sakai et al., 2002). We measured sensitization to repeated cocaine injections, using the activity boxes previously used to track the habituation of basal activity. str-KCREB mice and sibling controls both showed increasing locomotor sensitization across several days of cocaine at a dose of $5 \mathrm{mg} / \mathrm{kg}$ i.p. (Figure 8A). ANOVA for repeated measures revealed significant main effects of genotype $\left(F_{1,55}=11.92\right.$, $P<0.001)$, and treatment $\left(F_{1,55}=242.25, P<0.0001\right)$ and a significant genotype-treatment interaction $\left(F_{1,55}=12.64, P<0.001\right)$. str-KCREB mice showed markedly increased sensitization relative to controls, with a difference first becoming apparent on the second day of drug exposure and persisting throughout five consecutive sessions (Scheffé test, str-KCREB vs WT on day 5: $P<0.01$; from days 6 to 10: $P<0.0001)$. After 7 days of cocaine the animals were injected with saline (day 11); no difference between mutant and control mice was seen. When re-exposed to cocaine 10 days later, all mice continued to show a facilitated response, with str-KCREB mice remaining more active than controls (day 12, Scheffé test $P<0.05)$.

When we used a higher dose of cocaine $(15 \mathrm{mg} / \mathrm{kg}$, i.p.) we observed a significantly increased level of activity due to chronic treatment (ANOVA for repeated measure, $F_{3,51}=110.37$, $P<0.001)$ but the difference between transgenics and controls was no longer apparent (Figure 8B). As with cocaine CPP, this may be due to a ceiling effect; indeed, transgenics and controls achieved a near-maximum level of activity on the first day of this higher dose of cocaine, with little or no sensitization thereafter.

Altogether, these results indicate that inhibition of CREB activity in the dorsal portion of the striatum significantly elevates the behavioral sensitivity to drugs of abuse such as cocaine and morphine.

\section{DISCUSSION}

We have previously shown that disruption of striatal CREB-regulated transcription results in impairments of corticostriatal LTP and LTD in the dorsal striatum (but not in the NAc) and of several striatum-dependent memory tasks (Pittenger et al., 2006). In contrast, with the present work we demonstrated that the same genetic manipulation enhances CPP to cocaine and morphine as well as locomotor sensitization to repeated cocaine administration, two behavioral paradigms commonly used to study early phases of drug addiction.

Our new findings raise at least two important issues. The first is about the contrasting action of CREB in "normal" striatumdependent memory and in reward-related learning. The second concerns the role of CREB in the dorsal striatum vs the NAc.

A large body of evidence accumulated in the past decade has clearly indicated that drugs of abuse exploit intracellular signaling pathways normally implicated in memory formation. One of the best characterized examples is the Ras-ERK pathway, which is required in a number of brain regions to convert short-term memory traces into their long-term, protein-dependent forms (Orban et al., 1999; Adams and Sweatt, 2002; Sweatt, 2004; Davis and Laroche, 2006). Pharmacological blockade of ERK signaling with SL327 in vivo leads not only to memory impairments but also to inhibition of locomotor sensitization and CPP to cocaine (see the original reports in Atkins et al., 1998; Valjent et al., 2000). In addition, genetic experiments in the mouse, using for instance ERK1 and Ras-GRF1 mutant mice, has revealed that the potentiation of the ERK pathway in the striatum leads not only to a facilitation of procedural learning but also to an increase sensitivity to psychostimulants and opiates, suggesting that the same signaling alteration promotes both behaviors. Conversely, genetic alterations that impair procedural memory also inhibit responses to drugs (Brambilla et al., 1997; Mazzucchelli et al., 2002; Ferguson et al., 2006; Fasano et al., 2009).

Since the ERK pathway is a key activator of CREB-dependent transcription in the brain (Xing et al., 1996), it is therefore surprising that CREB inhibition in the str-KCREB mice causes contrasting effects on memory formation and responses to drugs. One explanation for such a paradoxical difference may be that 


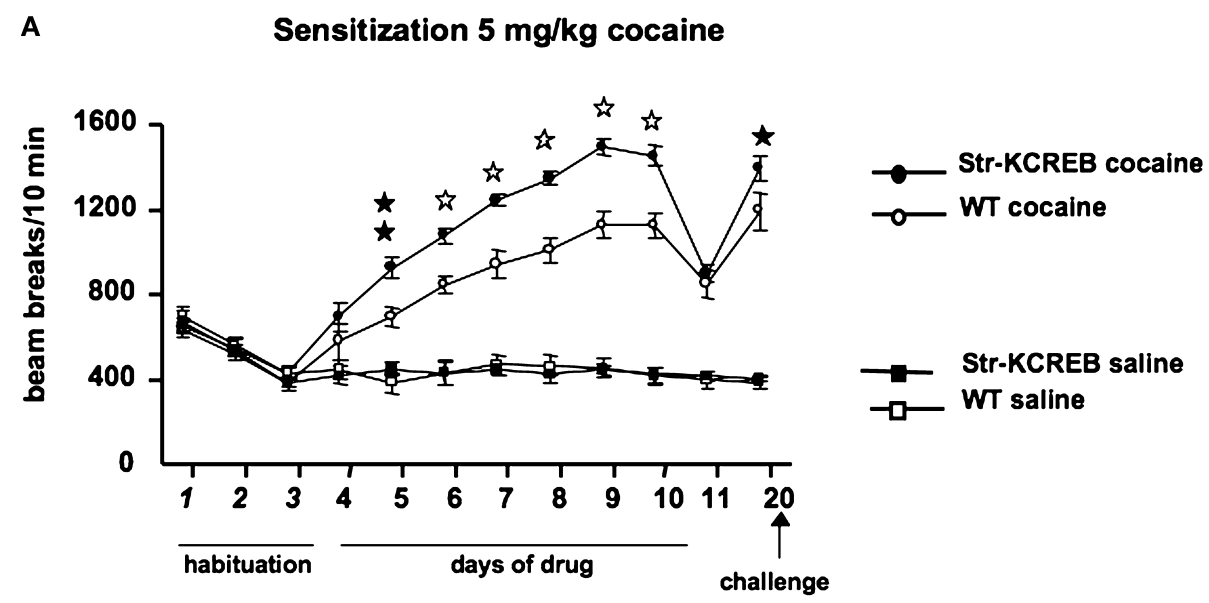

B Sensitization $15 \mathrm{mg} / \mathrm{kg}$ cocaine

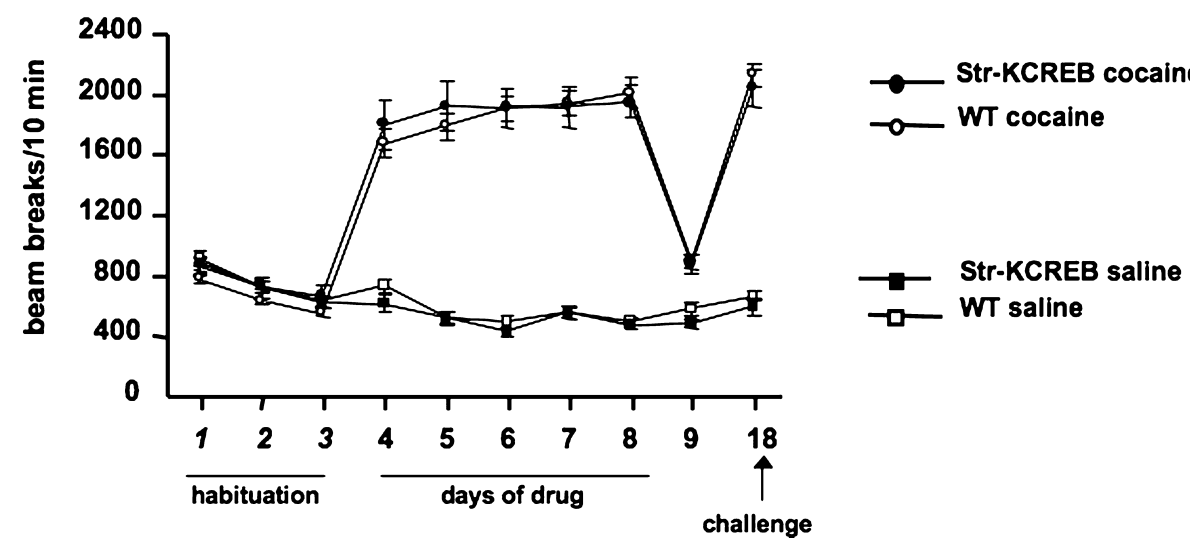

FIGURE 8 | Enhanced locomotor sensitization induced by cocaine in str-KCREB mice. (A) str-KCREB mice showed enhanced locomotor sensitization to $5 \mathrm{mg} / \mathrm{kg}$ cocaine. After 3 days of habituation, str-KCREB mice show increased locomotor sensitization across 7 days of cocaine ( $n=16$ transgenic, 18 control) or saline ( $n=12$ transgenic, 15 control; all values mean \pm SEM). (B) Locomotor sensitization was normal with a higher dose of cocaine $(15 \mathrm{mg} / \mathrm{kg})$, possibly representing a ceiling effect ( $n=12$ transgenic, 16 control) or saline ( $n=12$ transgenic, 15 control; all values mean \pm SEM). Genotype effect: ${ }^{*} P<0.05$; ${ }^{*} P<0.01$; * $P<0.0001$. a marked and chronic inhibition of CREB, as in the str-KCREB mice, could lead to unique cellular adaptations in response to strong environmental stimuli such as drug administration. This in turn may preferentially affect genes that normally constrain drug-mediated behavioral responses, thus increasing sensitivity to drugs. One class of such CREB-regulated genes may well be that of opioid peptides, including dynorphin whose increased expression in the NAc may contribute to the aversive-like symptoms observed in transgenic mice overexpressing WT CREB (Carlezon et al., 2005). Interestingly, we previously observed a reduced basal expression of the proenkephalin gene, another opiod peptide, in the dorsal striatum of our str-KCREB animals (Pittenger et al., 2002). Indeed genes regulated by CREB activity are different when acute cocaine vs chronic cocaine treatments are compared (McClung and Nestler, 2003). Therefore, it is likely that CREB inhibition observed during either a pharmacogenetic blockade of ERK signaling or during normal procedural learning in the str-KCREB mice may not be sufficient to affect the same genetic programs altered upon chronic drug treatment, thus producing only a general shutdown of genes involved in synaptic plasticity and memory mechanisms. In this respect it is important to note that previous evidence strongly supported the idea that some drugs of abuse, including those used in this study, increase intracellular signaling in the striatum, thereby increasing CREB levels (for review see Carlezon et al., 2005). This CREB upregulation may function as a homeostatic mechanism. According to this view, increased CREB activation may contribute to habituation: it leads to a reduction in some drug responses upon subsequent drug exposure (Carlezon et al., 1998; Barrot et al., 2002; Sakai et al., 2002). It is thus conceivable that CREB inhibition in the str-KCREB mice prevents such drugdependent upregulation of CREB, leading to facilitated behavioral responses.

The dorsal and ventral striatum differ not only in their connectivity and neurochemistry but also in their involvement in different behavioral responses (Voorn et al., 2004; Everitt and Robbins, 2005). Traditionally the ventral portion of the striatum, including the NAc has been associated with the reward aspects of 
learning and of drug administration, while the dorsal portion of the striatum has been implicated in motor control and "skills and habits." Habit learning has been invoked to explain certain aspects of drug addiction involved in the transition from goal-directed behavior to compulsive habit formation. This transition is supposed to be accompanied by temporally distinct synaptic modifications in both ventral and dorsal striatum, which lead to a progressive ventral to dorsal dominance shift (Robbins and Everitt, 1999; Cardinal et al., 2002; Cardinal and Everitt, 2004; Belin and Everitt, 2008; Belin et al., 2008, 2009).

One of the prediction of such model would be that while alterations in the NAc should affect early phases of the addiction process, in which a compulsive habit has not been yet established, synaptic modifications in the dorsal portion should only impact of later phases. Indeed specific CREB manipulations in the NAc affect cocaine and morphine CPP (Carlezon et al., 1998, 2005; Pliakas et al., 2001; Barrot et al., 2002; Dinieri et al., 2009), which results from only a few drug treatments.

\section{REFERENCES}

Adams, J. P., and Sweatt, J. D. (2002). MOLECULAR PSYCHOLOGY: roles for the ERK MAP kinase cascade in memory. Annu. Rev. Pharmacol. Toxicol. 42, 135-163.

Ahn, S., Ginty, D. D., and Linden, D. J. (1999). A late phase of cerebellar longterm depression requires activation of CaMKIV and CREB. Neuron 23, 559-568.

Atkins, C. M., Selcher, J. C., Petraitis, J. J., Trzaskos, J. M., and Sweatt, J. D. (1998). The MAPK cascade is required for mammalian associative learning. Nat. Neurosci. 1, 602-609.

Barco,A., Alarcon, J. M., and Kandel, E. R. (2002). Expression of constitutively active CREB protein facilitates the late phase of long-term potentiation by enhancing synaptic capture. Cell 108, 689-703.

Barco, A., Patterson, S., Alarcon, J. M., Gromova, P., Mata-Roig, M., Morozov, A., and Kandel, E. R. (2005). Gene expression profiling of facilitated L-LTP in VP16-CREB mice reveals that BDNF is critical for the maintenance of LTP and its synaptic capture. Neuron 48, 123-137.

Barco, A., Pittenger, C., and Kandel, E. R. (2003). CREB, memory enhancement and the treatment of memory disorders: promises, pitfalls and prospects. Expert Opin. Ther. Targets 7, 101-114.

Barrot, M., Olivier, J. D., Perrotti, L. I., DiLeone, R. J., Berton, O., Eisch, A. J., Impey, S., Storm, D. R., Neve, R. L., Yin, J. C., Zachariou, V., and Nestler, E. J. (2002). CREB activity in the nucleus accumbens shell controls gating of behavioral responses to emotional stimuli. Proc. Natl. Acad. Sci. USA 99, 11435-11440.
Bartsch, D., Casadio, A., Karl, K. A., Serodio, P., and Kandel, E. R. (1998). CREB1 encodes a nuclear activator, a repressor, and a cytoplasmic modulator that form a regulatory unit critical for long-term facilitation. Cell 95, 211-223.

Belin, D., and Everitt, B. J. (2008). Cocaine seeking habits depend upon dopamine-dependent serial connectivity linking the ventral with the dorsal striatum. Neuron 57, 432-441.

Belin, D., Jonkman, S., Dickinson, A., Robbins, T. W., and Everitt, B. J. (2009). Parallel and interactive learning processes within the basal ganglia: Relevance for the understanding of addiction. Behav. Brain Res. 199 89-102.

Belin, D., Mar, A. C., Dalley, J. W., Robbins, T.W., and Everitt, B. J. (2008). High impulsivity predicts the switch to compulsive cocaine-taking. Science 320, 1352-1355.

Berke, J. D., and Hyman, S. E. (2000). Addiction, dopamine, and the molecular mechanisms of memory. Neuron 25, 515-532.

Bourtchuladze, B., Frenguelli, B., Blendy, J., Cioffi, D., Schutz, G., and Silva, A. J. (1994). Deficient long-term memory in mice with a targeted mutation of the cAMP-responsive elementbinding protein. Cell 79, 59-68.

Brambilla, R., Gnesutta, N., Minichiello, L., White, G., Roylance,A.J.,Herron, C. E., Ramsey, M., Wolfer, D. P., Cestari, V., Rossi-Arnaud, C., Grant, S. G., Chapman, P. F., Lipp, H. P., Sturani, E., and Klein, R. (1997). A role for the Ras signalling pathway in synaptic transmission and long-term memory. Nature 390, 281-286.

Cardinal, R. N., and Everitt, B. J. (2004). Neural and psychological mechanisms

Our results suggest for the first time that inhibition of CREB in the dorsal portion of the striatum may significantly contribute to changes in the rewarding properties of both cocaine and morphine, as well as to cocaine sensitization, in a manner which appears to be similar to what observed with the NAc manipulations. This observation suggest that CREB activity in the dorsal striatum may share common functions with those observed in the NAc, pointing to a more integrated role of both striatal regions in the early phases of drug addiction.

\section{ACKNOWLEDGMENTS}

This work was supported by the Italian Ministry for the University and Research (MIUR) and by the Mariani Foundation for Neurological Research (to Riccardo Brambilla), and by NIMH grants F31 MH 012955 and K08 MH 081190, and a NARSAD Young Investigator Award (to Christopher Pittenger). The authors thank Eric Kandel for his support in the generation and early characterization of the str-KCREB transgenic mice.

underlying appetitive learning: links to drug addiction. Curr. Opin. Neurobiol. 14, 156-162.

Cardinal, R. N., Parkinson, J. A., Hall, J., and Everitt, B. J. (2002). Emotion and motivation: the role of the amygdala, ventral striatum, and prefrontal cortex. Neurosci. Biobehav. Rev. 26, 321-352.

Carlezon, W. A. Jr., Duman, R. S., and Nestler, E. J. (2005). The many faces of CREB. Trends Neurosci 28, 436-445.

Carlezon, W.A. Jr., Thome, J., Olson, V. G., Lane-Ladd, S. B., Brodkin, E. S., Hiroi, N., Duman, R. S., Neve, R. L., and Nestler, E. J. (1998). Regulation of cocaine reward by CREB. Science 282, 2272-2275.

Chao, J., and Nestler,E. J.(2004). Molecular neurobiology of drug addiction. Annu. Rev. Med. 55, 113-132.

Dash, P. K., Hochner, B., and Kandel, E. R. (1990). Injection of the cAMPresponsive element into the nucleus of Aplysia sensory neurons blocks long-term facilitation. Nature 345, 718-721.

Davis, S., and Laroche, S. (2006). Mitogenactivated protein kinase/extracellular regulated kinase signalling and memory stabilization: a review. Genes Brain Behav. 5(Suppl. 2), 61-72.

Dinieri, J. A., Nemeth, C. L., Parsegian, A., Carle, T., Gurevich, V.V., Gurevich, E., Neve, R. L., Nestler, E. J., and Carlezon, W. A. Jr. (2009). Altered sensitivity to rewarding and aversive drugs in mice with inducible disruption of cAMP response elementbinding protein function within the nucleus accumbens. J. Neurosci. 29, 1855-1859.

Dong, Y., Green, T., Saal, D., Marie, H. Neve, R., Nestler, E. J., and Malenka, R. C. (2006). CREB modulates excitability of nucleus accumbens neurons. Nat. Neurosci. 9, 475-477.

Everitt, B. J., and Robbins, T. W. (2005). Neural systems of reinforcement for drug addiction: from actions to habits to compulsion. Nat. Neurosci. 8, 1481-1489.

Fasano, S., and Brambilla, R. (2002). Cellular mechanisms of striatumdependent behavioral plasticity and drug addiction. Curr. Mol. Med. 2, 649-665.

Fasano, S., D’Antoni, A., Orban, P. C., Valjent, E., Putignano, E., Vara, H. Pizzorusso, T., Giustetto, M., Yoon, B., Soloway, P., Maldonado, R., Caboche, J., and Brambilla, R. (2009). Ras-guanine nucleotide-releasing factor 1 (RasGRF1) controls activation of extracellular signal-regulated kinase (ERK) signaling in the striatum and long-term behavioral responses to cocaine. Biol. Psychiatry. [Epub ahead of print]

Ferguson, S. M., Fasano, S., Yang, P., Brambilla, R., and Robinson, T. E. (2006). Knockout of ERK1 enhances cocaine-evoked immediate early gene expression and behavioral plasticity. Neuropsychopharmacology 31, 2660-2668.

Han, J. H., Kushner, S. A., Yiu, A. P., Cole, C. J., Matynia, A., Brown, R. A., Neve, R. L., Guzowski, J. F., Silva, A. J., and Josselyn, S. A. (2007). Neuronal competition and selection during memory formation. Science 316, 457-460.

Han, J. H., Kushner, S. A., Yiu, A. P., Hsiang, H. L., Buch, T., Waisman, A., Bontempi, B., Neve, R. L., Frankland, P. W., and Josselyn, S. A. (2009). Selective erasure of a fear memory. Science 323, 1492-1496.

Hernandez, P. J., Sadeghian, K., and Kelley, A. E. (2002). Early 
consolidation of instrumental learning requires protein synthesis in the nucleus accumbens. Nat. Neurosci. 5, 1327-1331.

Hyman, S. E., Malenka, R. C., and Nestler, E. J. (2006). Neural mechanisms of addiction: the role of reward-related learning and memory. Annu. Rev. Neurosci. 29, 565-598.

Jancic, D., Lopez de Armentia, M., Valor, L. M., Olivares, R., and Barco, A. (2009). Inhibition of cAMP response element-binding protein reduces neuronal excitability and plasticity, and triggers neurodegeneration. Cereb. Cortex. doi: 10.1093/cercor/bhp004. [Epub ahead of print].

Josselyn, S. A., Kida, S., and Silva, A. J. (2004). Inducible repression of CREB function disrupts amygdaladependent memory. Neurobiol. Learn. Mem. 82, 159-163.

Josselyn, S. A., and Nguyen, P. V. (2005). CREB, synapses and memory disorders: past progress and future challenges. Curr. Drug Targets 4, 481-497.

Josselyn, S. A., Shi, C., Carlezon, W. A. Jr., Neve, R. L., Nestler, E. J., and Davis, M. (2001). Long-term memory is facilitated by cAMP response elementbinding protein overexpression in the amygdala. J. Neurosci. 21, 2404-2412.

Kelley,A.E. (2004). Memory and addiction: shared neural circuitry and molecular mechanisms. Neuron 44, 161-179.

Kida, S., Josselyn, S. A., de Ortiz, S. P., Kogan, J.H., Chevere, I., Masushige, S., and Silva, A. J. (2002). CREB required for the stability of new and reactivated fear memories. Nat. Neurosci. 5, 348-355.

Lee, A. S., Duman, R. S., and Pittenger, C. (2008). A double dissociation revealing bidirectional competition between striatum and hippocampus during learning. Proc. Natl. Acad. Sci. USA 105, 17163-17168.

Lopez de Armentia, M., Jancic, D., Olivares, R., Alarcon, J. M., Kandel, E. R., and Barco, A. (2007). cAMP response element-binding protein-mediated gene expression increases the intrinsic excitability of CA1 pyramidal neurons. J. Neurosci. 27, 13909-13918.

Maldonado, R., Saiardi, A., Valverde, O., Samad, T. A., Roques, B. P., and Borrelli, E. (1997). Absence of opiate rewarding effects in mice lacking dopamine D2 receptors. Nature 388, 586-589.

Mamiya, N., Fukushima, H., Suzuki, A., Matsuyama, Z., Homma, S., Frankland, P. W., and Kida, S. (2009). Brain region-specific gene expression activation required for reconsolidation and extinction of contextual fear memory. J. Neurosci. 29, 402-413.

Mantamadiotis, T., Lemberger, T., Bleckmann, S. C., Kern, H., Kretz, O., Martin Villalba, A., Tronche, F., Kellendonk, C., Gau, D., Kapfhammer, J., Otto, C., Schmid, W., and Schütz, G. (2002). Disruption of CREB function in brain leads to neurodegeneration. Nat. Genet. 31, $47-54$.

Mazzucchelli, C., Vantaggiato, C., Ciamei, A., Fasano, S., Porrazzo, A., Orban, P. C., Pakhotin, P., Krezel, W., Wezl, H., Wolfer, D. P., Pages, G., Valverde, O., Marowsky, A., Maldonado, R., Ehrengruber, M. U., Cestari, V., Lipp, H. -P., Chapman, P. F., Pouyssegur, J., and Brambilla, R. (2002). Knockout of ERK1 MAP kinase enhances synaptic plasticity in the striatum and facilitates striatalmediated learning and memory. Neuron 34, 807-820.

McClung, C. A., and Nestler, E. J. (2003). Regulation of gene expression and cocainerewardbyCREB andDeltaFosB. Nat. Neurosci. 6, 1208-1215.

Orban, P. C., Chapman, P. F., and Brambilla, R. (1999). Is the RasMAPK signalling pathway necessary for long-term memory formation? Trends Neurosci. 22, 38-44.

Pittenger, C., Fasano, S., MazzocchiJones, D., Dunnett, S. B., Kandel, E. R., and Brambilla, R. (2006). Impaired bidirectional synaptic plasticity and procedural memory formation in striatum-specific cAMP response element-binding protein-deficient mice. J. Neurosci. 26, 2808-2813.

Pittenger, C., Huang, Y. Y., Paletzki, R. F., Bourtchouladze, R., Scanlin, H., Vronskaya, S., and Kandel, E. R. (2002). Reversible inhibition of CREB/ATF transcription factors in region CAl of the dorsal hippocampus disrupts hippocampus-dependent spatial memory. Neuron 34, 447-462.

Pliakas, A. M., Carlson, R. R., Neve, R. L., Konradi, C., Nestler, E. J., and Carlezon, W. A. Jr. (2001). Altered responsiveness to cocaine and increased immobility in the forced swim test associated with elevated cAMP response element-binding protein expression in nucleus accumbens. J. Neurosci. 21, 7397-7403.

Robbins, T. W., and Everitt, B. J. (1999). Drug addiction: bad habits add up. Nature 398, 567-570.

Robinson, T. E., and Berridge, K. C. (1993). The neural basis of drug craving: an incentive-sensitization theory of addiction. Brain Res. Brain Res. Rev. $18,247-291$.

Sakai, N., Thome, J., Newton, S. S., Chen, J., Kelz, M. B., Steffen, C., Nestler, E. J., and Duman, R. S. (2002). Inducible and brain region-specific CREB transgenic mice. Mol. Pharmacol. 61, 1453-1464.

Sweatt, J. D. (2004). Mitogen-activated protein kinases in synaptic plasticity and memory. Curr. Opin. Neurobiol. 14,311-317.

Valjent, E., Corvol, J. C., Pages, C., Besson, M. J., Maldonado, R., and Caboche, J. (2000). Involvement of the extracellular signal-regulated kinase cascade for cocaine-rewarding properties. J. Neurosci. 20, 8701-8709.

Viosca, J., Lopez de Armentia, M., Jancic, D., and Barco, A. (2009a). Enhanced CREB-dependent gene expression increases the excitability of neurons in the basal amygdala and primes the consolidation of contextual and cued fear memory. Learn. Mem. 16, 193-197.

Viosca, J., Malleret, G., Bourtchouladze, R., Benito, E., Vronskava, S., Kandel, E. R., and Barco, A. (2009b). Chronic enhancement of CREB activity in the hippocampus interferes with the retrieval of spatial information. Learn. Mem. 16, 198-209.

Voorn, P., Vanderschuren, L. J., Groenewegen, H. J., Robbins, T. W., and Pennartz, C. M. (2004). Putting a spin on the dorsal-ventral divide of the striatum. Trends Neurosci. 27, 468-474.

Walters, C. L., and Blendy, J. A. (2001). Different requirements for cAMP response element binding protein in positive and negative reinforcing properties of drugs of abuse. J. Neurosci. 21 , 9438-9444.

Xing, J., Ginty, D. D., and Greenberg, M. E. (1996). Coupling of the RAS-MAPK pathway to gene activation by RSK2, a growth factor-regulated CREB kinase. Science 273, 959-963.

Yin, J. C., Wallach, J. S., Del Vecchio, M., Wilder, E. L., Zhou, H., Quinn, W. G., and Tully, T. (1994). Induction of a dominant negative CREB transgene specifically blocks long-term memory in Drosophila. Cell 79, 49-58.

Conflict of Interest Statement: The authors declare that the research was conducted in the absence of any commercial or financial relationships that could be construed as a potential conflict of interest.

Received: 28 April 2009; paper pending published: 23 June 2009; accepted: 23 August 2009; published online: 09 September 2009.

Citation: $S$ Fasano, $C$ Pittenger and $R$ Brambilla (2009) Inhibition of CREB activity in the dorsal portion of the striatum potentiates behavioral responses to drugs of abuse. Front. Behav. Neurosci. 3:29. doi: 10.3389/neuro.08.029.2009

Copyright $\odot 2009$ Fasano, Pittenger and Brambilla. This is an open-access article subject to an exclusive license agreement between the authors and the Frontiers Research Foundation, which permits unrestricted use, distribution, and reproduction in any medium, provided the original authors and source are credited. 